\title{
Citizenship, Leisure and Gender Equality
}

\author{
Lisbeth Lindström ${ }^{1}$ \\ ${ }^{1}$ Dr in Education/Social Sciences, Department of Culture, Communication and Learning, Luleå University of \\ Technology, Sweden \\ Correspondence: Lisbeth Lindström, Dr in Education/Social Sciences, Department of Culture, Communication \\ and Learning, Luleå University of Technology, SE-97187 Luleå, Sweden. E-mail: Lisbeth.Lindstrom@ltu.se
}

\author{
Received: May 15, 2012 Accepted: June 4, 2012 Online Published: August 7, 2012 \\ doi:10.5539/ies.v5n5p57 URL: http://dx.doi.org/10.5539/ies.v5n5p57
}

\begin{abstract}
This article explores the relationship between gender, citizenship and leisure activities for youth. The purpose with the article is to describe, explore and discuss whether meeting places for youth such as youth clubs support their citizenship. Based on a case study of young people place, space and activities are explored and discussed from a gender perspective. To collect data, several study visits have been done during a six month period, involving visiting all of the youth clubs and similar meeting places as part of the case study. As a research method textual analysis of daily diaries written by youth leaders were used. The result of the case study shows firstly that these places are more attractive to boys than to girls. Secondly, they can be places for the development of youth citizenship. Thirdly, visitors are offered the opportunity of taking an active role in their own transition to citizenship.
\end{abstract}

Keywords: gender, citizenship, youth, case study

\section{Introduction}

In this article I consider the relationship between gender equality and citizenship. Based on a case study of young people's visiting youth clubs and similar meeting places, the diaries written by youth leaders are explored and discussed from a perspective of citizenship and gender.

Many young people spend their time at youth clubs, particularly boys who mistrust the school system. We know very little about their expectations regarding these visits or those of girls entering the leisure sector and attending youth clubs. We also know very little about what the attraction of these meeting places are, why they go there, the fulfillments of their needs as well as the development of their skills (Lindström, 2009).

Earlier research from the 1980's has found that boys are more active and frequently engaged in more exploratory activities (Block, 1983; Eaton \& Enns, 1986) and that they tend to be more aggressive. Compared to boys, girls were found to prefer manual activities like drawing, painting, and cutting and pasting and they were more often found to be in the arts and crafts area (Pellegrini \& Perlmutter, 1989). Furthermore they were found to prefer singing, dancing and dressing up. Boys were found to use a greater degree of space and play outdoors more often (Pomerleau, Bolduc, Malcuit \& Cossette, 1990).

For Swedish authorities like the government, county councils and local councils, leisure is an important link in the process of encouraging young people to become democratic, participatory and active citizens. Resources have been put into the leisure sector, distributed by the National Board for Youth Affairs, for different projects aimed at supporting young people's initiatives. Swedish authorities have seen youth clubs and similar meeting places for youths as an arena for the development of young persons' citizenship, and an interesting question is whether this contributes to the development of young people's citizenship, both male and female.

Shaw (1994) argues that leisure is not a gender-neutral aspect of social life and Connell (1987) claims that we need to understand the power relations between male and female in voluntary organizations such as clubs. Arnot (2006) state the relationship between gender and citizenship is complex and needs to be debated more openly and thoroughly. For example Parkin (2000) argues that in order to participate in citizenship here and now girls have to be able to take active positions in social, cultural, embodied and spatial relations. 


\subsection{Meeting Places for Youth}

The main characteristic of the local council's youth clubs and similar meeting places such as house of youth or house of all activities is that the leisure activities should be open for everyone whenever he/she wants to visit the club. These meeting places are open for all young people from the ages 13-25 and they are almost free of charge. It is possible for the young people to come and go whenever they want and there are no demands to 'do' things. They can just hang around or take part in the offered activities, such as table tennis, parlour games and so forth. The visitors may start activities from their own interests, such as forming a film club or making outdoor trips. When I use the word youth leader it refers civil servants who work at youth clubs and similar meeting places. Youth clubs and similar meeting places are sometimes run and organized by the local councils themselves or at other times organized by organizations and associations and run with funds from the local councils.

Drawing on a study of daily notes made in diaries of youth leaders in five youth clubs and one meeting places in a Swedish local council in a county council in the North of Sweden, is aspects of young people's citizenship discussed.

The purpose of this article therefore is firstly to fulfil the gap between theories of citizenship and gender and the actual practice. Secondly, to describe, explore and discuss whether these meeting places for youth support their citizenship as expressed by staff in daily notes in diaries and in the terms of the core values gender equality, accessibility, sustainability, integration, influence and participation.

The disposition of the article is as follows. In the chapter 'Citizenship, gender and youth leisure' I give a brief description of the conception of citizenship and to gender research connected to youth leisure. In the next section, 'The present study', the research design is presented, the method for data collection, method of analysis and the implementation of the study. The empirical study is presented under the headline 'An ordinary quiet evening' divided into five sections; activities, integration and accessibility, gender equality, influence and participation and finally safety and sustainability. In the final section I discuss my findings.

\section{Citizenship, Gender and Youth Leisure}

Arnot and Dillabough (2000) have argued that an important aspect of schooling is the production of citizenship (Gordon, 2006).

However, Arnot (2009) claims that from a global perspective, educational systems are most likely to have embedded within them the conventional gender boundaries and hierarchies, producing and reproducing the hierarchies and power of masculinity that are associated with women's oppression as well as traditional forms of femininity.

A citizen may be described as a member of a political community or a state, who has certain legal, social and moral rights, duties and responsibilities. Citizenship is a political concept with a variety of rights and responsibilities in a given political community. These rights and responsibilities change over time as the result of social struggle, economic change and shifts in governing ideology. The right to vote and hold office is a cornerstone of democratic theory and practice (McDonagh, 2002; Schild, Pererva \& Stockwell, 2009; Kovacheva \& Pohl, 2007).

Meer and Sever (2004) argue that people define their citizenship in many different ways, in relation to the local, national or global community. Citizenship is both a status or an identity and a practice or process of relating to the social world through the exercise of rights/protections and the fulfilment of obligations. Like power relations, citizenship rights are not fixed, but are objects of struggle to be defended, reinterpreted and extended (Arnot, 1997).

Much of what is written today about citizenship originates in the theories of Marshall in the 1950s (Marshall \& Bottomore, 1996; O'Connor, 1993).

Marshall's conclusions have been criticised, however, primarily because the conception essentially describes male citizenship (Mouffe, 1992; Turner, 1993; Lister, 1997; Torres, 1998; Arnot, 2006; Ahmad, 2006; Faulks, 2006; Lockyer, 2003; Gordon, 2006).

Yuval-Davis (1997) criticises Marshall because social division and social position such as gender, ethnicity, class and so forth have not been problematized in his work. She stresses that these aspects are crucial to the construction of citizenship as well as individuality. Furthermore, she argues that Marshall's definition of citizenship as membership of a community rather than of the state is too vague. She contends that his notion of citizenship is too narrow because of people's membership in different communities wherein citizens can have 
different possibilities and positions depending on, for example, gender or ethnicity (Yuval-Davis, 2002; Banks, 2008)

Pnina Werbner and Yuval-Davis (1999) claim modern citizenship is a social and political construction that defines the limits of state power and where a civil society or the private sphere of free individuals begins. Eckert \& McConnell-Ginet (1995) and Shaw (1994) argue that gender is not a matter of two homogeneous social categories associated with being female and the other with being male. Gender constructs are embedded in other aspects of social life and in the construction of other socially significant categories such as those involving class, race or ethnicity.

\subsection{The Use of Spaces and Voices}

Helve (2001) has investigated the value structure among young people in Europe in order to find out their ideological preferences. The ages she investigated ranged from 16 to 19. Significant differences in boys and girls' values were found. Girls valued environmental issues more than the boys and the latter valued technology and science more than girls. With respect to gender differences, girls valued humanism and equality more than boys, who valued technology and economic welfare more (ibid). This means that the same young person may choose the position of an individualist in some situations and of a humanist in others.

Similarly, Eckert and McConnell-Ginet (1995) claim that during the course of people's lives they move into, out of and through communities of practice, continually transforming identities, understanding, and world view.

Gordon, Holland and Lahelma (2000) state that bodies in space are constructed as female or male and, furthermore that different expectations are inscribed on them. The use of voice is, they argue, complex for girls. In research school girls were found to be more passive in space and their bodies were supposed to be more contained and their voices quieter. Girls tried to invade a physical space in an embodied way rather than be metaphorical invaders of space. Silent girls were found to often mask pain and disappointments but could also provide an enabling space where girls could concentrate on educational achievement or on their own fantasies (Eckert and McConnell-Ginet, 1995).

In earlier research, West and Zimmerman (1987) argued in their groundbreaking article that an understanding of how gender is produced in social situations will afford clarification of the interactional scaffolding of social structure and the social control processes that sustain it. Twenty years later Deutsch (2007) claimed that we need a shift from discussions about the creation of doing gender to illuminating how we can undo gender. She proposed an adoption of a new convention to reserve the phrase 'doing gender' to refer to social interactions that reproduce gender difference and use the phrase 'undoing gender' to refer to social interactions that reduce gender differences.

\section{The Present Study}

To give a partial picture of how citizenship and gender relations are being mutually constructed in this particular setting - the youth club and similar meeting places - a case study was thought to offer the optimal research strategy.

An ambition was to bridge the gap between gender and citizenship, to study what notes staff have made about occurrences of youth influence, participation, opportunities and gender issues at youth clubs and similar meeting places. This case study is an empirical inquiry that investigates a phenomenon within its real-life context (Yin, 1994; Alvesson \& Sköldberg, 1994).

The following questions were of special interest; what information was discovered about how boys and girls talk about themselves and to others? What information was discovered about how and if young people integrate? What information was discovered about staff and how visitors use the physical environment and the facilities and by whom are they used? What information was discovered by staff about the possibility of visitors to influence and participate and the accessibility and sustainability of youth clubs and other meeting places? Finally, what can be discovered about rules, norms and values?

\subsection{Research Design}

The case study is conducted in an area which consists of thirteen local councils in the county council of Norrbotten in the north of Sweden. The county council has about 240,000 inhabitants and the local council has about 73,000 inhabitants. The choice of this particular local council was due to its number of meeting places for young people and its location in the north of Sweden. The research, embraces five youth clubs and one meeting place for youth in the particular local council. In 2009, about 12,699 young people between the ages of 13-24 years old, were resident there. 
The research focused on one meeting place, here labelled the Buttercup and five youth clubs here referred to as the Petunia, the Bluebell, the Viola, the Marguerite and the Orchid. Their opening ours were Tuesday-Thursday, 18:00-21:00 and weekends 18:00-23:00. The local council itself runs one of the places the youth club called the Viola. The other four youth clubs are run by an economic association on assignment from the local council.

The meeting place called the Buttercup is a place situated about four kilometres outside the city centre close to a compulsory school and a sports auditorium. In the area, both housing estates and houses exist although there are no companies or factories established in the neighbourhood. Most of the visitors to the Buttercup are males up to 18 years old.

The youth club called the Viola is situated a few kilometers outside the city centre. The youth club is situated close to the compulsory school in a separate building. Close to the youth club is a centre for citizens, including children and young people, who have come as refugees to the local area. These consist of families who have already been granted asylum or it can be people of different ages and gender who are hoping for asylum. Most of the visitors are boys.

The youth club, called the Marguerite, is situated a few kilometers from the city centre. It is located in the centre of the residential area and is directly connected to a compulsory school, some grocery stores and a sport hall. The youth club has many rooms and areas of open space for their visitors to use. Some of the areas are used in the afternoons and shared with the nearby compulsory school. Most of the visitors to this youth club are boys.

Not far from youth club the Marguerite another youth club is situated, called the Petunia. The youth club is situated in the centre in the same building as a compulsory school. This is another youth club with a lot of space for their visitors. The staff has to walk between the different rooms that are a part of the youth club and can not see the spaces between them. Most of the visitors to the youth club are boys.

This youth club, called the Orchid is situated 30 kilometres from the city centre. The youth club is not situated in the centre of the suburban area. It is situated more than one kilometre outside the centre. In the centre one can find a sports hall, swimming pool, a few stores and the bus station. The youth club is located in an older building and close to the youth club one can find a smaller sports hall. The facilities, equipment and the building give an impression of being old and worn. The sports hall cannot be for used for visitors to the youth club. It is mostly boys visiting the youth club.

The youth club called the Bluebell is situated about five kilometres outside the city centre. It is located in the centre of the residential area and is directly connected to a compulsory school, a grocery store and a sports hall. The youth club has many rooms and areas of open space for their visitors to use. It is mostly boys visiting the youth club.

\subsection{Data Collection - diaries}

To fulfil the purpose of the research it was necessary to get a deeper understanding of the staffs owns experiences of young visitors at youth clubs and similar meeting places, from the perspective of citizenship and gender equality. As staff at the youth clubs and meeting places involved in this study wrote daily reflections in diaries and I also had the possibility to use these diaries, it was decided to collect this material at each particular youth club involved in the research project. Afterwards the diaries were copied and sent back to the different youth clubs and meeting places participating in this study. The research material covers notes kept in dairies during the year 2009.

The authors of these texts, who are youth leaders, have created a contextual coherence through naming different phenomenon and by using a specific discourse. That means that I use the leisure discourse as a general idea that language is structured according to different patterns that peoples' utterances follow when they take part in different domains of social life. Through this discourse, which delimitates or excludes certain things while it includes others, a reality is constructed (Philips \& Jörgensen, 2002). The world are constructed by individuals living in a historical and cultural context which is produced and reproduced by their speech acts in this case youth leaders working at youth clubs and similar meeting places. My task is to unveil what is expressed in the text and discern the contextual realities that have been constructed (Börjesson \& Palmblad, 2007). For example it might be possible to find out visitors and staff experiences about issues such as aspects of gender equality, integration, influence and participation to leisure. Information can be forthcoming about citizens' welfare, needs and expectations and their possibilities to influence these factors. In this research I am interested in what was explicitly stated in the texts of the diaries. This means that I focus on the way the texts were written, the content and in what context the texts were presented. Within the youth leader's notion of the contextual reality of the 
youth club and the meeting place and its contribution to young people's lives, I will analyze what kind of citizenship is expressed in the diaries through text analysis.

\subsection{Method of Analysis}

To analyze a text means to review the structure of the text and scrutinize the content, which is done through content analysis. Sometimes a text can consist of basic facts, sometimes of complicated interpretations and conclusions of linguistically constructed pictures of actuality or the state of something that actually exists objectively. For example a basic fact can be the number of visitors at a youth club, and how many are boys or girls. A statement of something that exists can be the presence of drugs at a youth club. There may even be complicated interpretations concerning the reason for referring young people with restraining orders from visiting the youth club.

There can be different voices and positions from which those who have written the texts express themselves and the situation. Sometimes a text contains counter-reaction or counter voices. The text can be homogeneous or heterogeneous, sometimes open and consistent in its attitude or sometimes masked under a veil of an objectified subject. I interpret this in the sense that a subjective value is understood as an objective truth (Alvesson \& Sköldberg, 1994; Mc Kee, 2003; Bruhn-Jensen, 1989).

\subsection{The Implementation of the Study}

Qualitative content analysis is used in this research because of the interest in how the text describes certain phenomena i.e. what standpoints youth leaders take and what arguments they present in the diaries (Kohlbacher, 2006). Furthermore, I was interested in what leisure activities are promoted and how the texts mirror values and norms. Subsequently, I want to examine how the texts talk about concepts such as gender equality, integration, influence and participation, how and in which context, these words are used.

The content analyses of texts proceeded through different stages. Firstly, each document was copied. The next step was to read through all of the material several times to find texts that had to do with young people and their visit at the youth clubs and the meeting places and make notes in relation to the notion of citizenship. Sometimes I have gone through and then returned to the texts for the selected youth clubs or meeting place. Through the whole process I have had the aim of the research questions in my mind and I used the theoretical perspective as a screen for the text. Notes were made about expressed citizenship, such as influence and participation, gender issues, committed resources and activities.

I have been observant of special words and statements, which seem to be relevant for the research questions, how they occur and in what order they occur. However rather than whether words such as gender equality, influence and democracy occur at all I am interested in how they occur and how they are discussed in the diaries and what kind of citizenship they represent. I further analyzed what kind of diction the different texts had, in what context the texts were written and what kinds of attitudes they expressed. Lastly I noted whether the reader of the text was invited to any kind of interaction. I also related the text to the context of how it was written and how leisure is connected to the civic society more generally. This can be seen in how staffers write about cooperation and collaboration with the civic society.

\section{An Ordinary Quiet Evening}

The headline of this part of the study, 'An ordinary quiet evening' or comments like 'A calm and common evening' show the most common note found in the diaries all categories of meeting places incorporated in this study. What a cosy evening (Buttercup), a harmonically atmosphere (Petunia), a calm evening with the ordinary visitors (Bluebell) and super duper night with lovely visitors (Orchid).

Daily notes from the diaries show that activities are often well structured with clear rules. Most of the visitors and the youth leaders know each other very well and routine activities are often going on as this quotation shows: Everyone is doing something (Petunia). Most of the visitors are boys frequently visiting the youth club or the meeting place. Notes like no girls (Orchid) are very common and in one diary the following note was made; the usual clientele were here (Bluebell).

Two female youth leaders describe in their daily entries in the diaries an occurrence which they suggest is one of the reasons for why they actually work as a youth leader: The best occurrence was when NN had courage and sang and played in the Café. It must be one of the most satisfying things with this work, to see young people's development $:($ Petunia).

Sometimes however, there emerge from the daily entries in the diaries examples of different episodes that youth leaders interpret as being serious or intractable. 
One of the female youth leaders wrote that she had to be angry at some of the visitors and complained about the necessity to be upset / ... it is not funny to have to be angry (Petunia). A new youth leader expressed that the visitors tested and provoked her. She is also very shocked over the language the visitors use. I am chocked over the language for example they use the world sieg heil (Petunia). Staff can even be provoked in other ways; some of the visitors sometimes want staff to believe that they have used drugs although youth clubs and meeting places for youth are drug free places: they provoke by pretending to be under the influence (Viola).

These episodes show how working as a youth leader is a qualified mission. Staffs have expectations from visitors to fulfil their personal goals. There are expectations from society such as parents, social authorities and the police to meet goals that go beyond simply offering a meeting place for young citizens

In this following section of the article I present the results of the empirical part of my study.

The purpose with this article is firstly to fulfil the gap between theories of citizenship and gender and practice. Secondly, to describe, explore and discuss whether these meeting places for youth support their citizenship as expressed by staff in daily notes in diaries and in the terms of the core values gender equality, accessibility, sustainability, integration, influence and participation.

Within the standpoint of theories of gender and citizenship, the results of the empirical study are structured within following categories; Activities and integration, gender equality, influence and participation and safety and sustainability.

\subsection{Activities and Integration}

From the diaries one can notice that activities at youth clubs and similar meeting place often are girls' activities such as drawing, painting and baking. Boys' activities are often to play billiards or table tennis.

Sometimes, especially during spring and autumn when the weather is more attractive to stay outdoors, the number of visitors at the youth clubs and the meeting places can be less than other times of the year; Something that following quotation confirms: The number of visitors are altogether very low, activities outdoor are more attractive which in itself is good, but a little boring for ME who works in empty premises (-)(Buttercup).

Several notes from the diaries show that particularly boys from other countries visit the youth clubs and similar meeting places. They often come together in a group, stay together at the club and play billiards together with their friends. In the diaries one can read that the guys were here and played billiards and listened to Arabic music and there were foreign visitors who played billiards (Orchid) or a number of totally new youths, very nice! (-), ordinary youths became quite and kind as candles 'FANNY' (Viola).

Some of these particular visitors are often coming alone from countries such as Afghanistan, Iraq or Somalia. They are waiting for a permanent decision concerning whether they can stay in Sweden or not. Others have been living in the area for several years. In the notes they are referred to as the 'asylum boys' or the 'immigrant boys'. Immigrant's children came at the end of the evening, funny or the asylum boys have been playing ping pong and billiards (Viola).

On one particular day in May, the youth leaders wrote reflections in their diaries about the visitors from abroad. It seems as though there had been a discussion about the possibilities of integration with other visitors at the youth club. The boys have been playing billiards. Do not know if they have been encouraged by their coaches (after we have been talking to them) to make more contacts. Because on both these days and on Saturday they have been asking us about how things are (Viola). Other notes verify that staff both observe and encourage these particular group of visitors to feel welcome. The 'immigrant boys' have really been taking space \& dominated the club together with the girls" (Viola) or NN started the ping pong tournament tonight again. Some of the 'asylum boys' joined them \& meet. It is fun that they dare intermix $@$ (Viola).

However, notes are also made about incidents or other comments about the challenge of integration. An incident between the 'asylum boy's \& the girls here (Viola). In one of the diaries one can read that youth leaders are upset about the attitudes among visitors. Sad that $N N, N N, N N$ (all males) $+N N$ (female) complain over the 'immigrant boys which they did when all of them had gone?!! Horrible (Viola).

However, notes also bear witness to the possibilities to overcome difficulties and stretch the boundaries with different groups of visitors / ... despite of what happened on Saturday of contradictions everyone behaved perfectly (Viola).

Notes in the diaries also show the occurrence of a dialogue about discrimination with the visitors. Have been talking with the youths about racism and questions about discrimination (Buttercup). At other times they talk about values and norms. Talked with the girls about sex and contraceptives \& relationships (Viola). Sometimes 
notes are made about discussions concerning how to behave or about being female or male and discussions about homosexuality, inequality, indignity, discrimination and so forth (Petunia) or discussed about racism and sexuality, active discussions! (Bluebell).

One of the staff wrote about her initiative to invite a friend who had 'come out' as homosexual but was disappointed when none of the youths dared to ask questions. I took the initiative to invite NN who is homosexual. Just to break the norm a little here tonight. Shame that no none dared to ask NN something (Viola).

Sometimes the discussions are even more philosophical and can be about young people's conception and philosophy of life. As usual some deep conversion with some of the visitors (Petunia; Bluebell). We had a serious talk about how to live our lives and about how to treat others the same way as you want to be treated yourself, wise words from the youths ... / (Petunia). These moments of more deep discussions or conversations were, on one occasion, found in the notes to be connected to the practice of values. Very nice talk about being young, and discussed ethical issues \& got a good conversation about boys \& thoughts (Petunia).

To work as a youth leader means accepting advice from experts regarding questions that are perceived as too complex to handle something which the following quotation shows. I have talked to the counselor today (Viola).

Several of the notes from the youth clubs bear witness to the complexities of working as a youth leader at youth clubs and similar meeting places, compared to, for example, working as a teacher. Young people in Sweden have to attend school by law. At youths young people come, go and stay of their own free will and in their own interests. If they are not attracted to the activities or interested in meeting staff and other visitors at the youth clubs they will probably not come back.

\subsection{Gender Equality}

The research clearly indicates that boys are more attracted to visiting youth clubs and meeting place in this local council than girls are. This phenomenon applies equally for all the places in this study, the boys are in the majority of visitors. If girls visit the youth clubs and the meeting place notes are often made from the staff in the diaries. Fun that a few girls have found their way here (Marguerite)) or unusually many girls (Orchid). Notes in one diary discusses how being a girl visiting a youth club can result in being subjected to sexually insulting language. $N N$ were nasty towards $N N$ (female) and said that she was a whore (Viola). Youth leaders indicate that this is not acceptable and the youth leaders often write to the replacement staff about reminding visitors about the language they use. You have to remind them about their language (Viola).

Sometimes, but not often notes are made about the number of boys, very calm evening from the beginning, but later a bunch of boys and a few girls dropped in (Marguerite). Sometimes, when new visitors come to the youth club notes are made about this event. Many new faces, mixed ages almost nearly boys here (Marguerite) or many new faces, FUNNY! (Petunia).

In one evening at one of the youth clubs they invited the visitors to come and eat a cake and to celebrate the youth clubs opening for the autumn semester. Afterwards the youth leaders made notes about their disappointment. We feel the preponderance of boys; just a few girls came (Marguerite). On the same day comments were made to the next staff to think about the sex distribution in different spaces and within the activities (Marguerite).

A couple of times during the year different events are arranged at some of the meeting places. There are days/evenings where they are open only for girls or for boys. These special times just for girls give possibilities to talk about things, such as how to do their hair or make up, about clothes, sex, norms and values. Sometimes they also have the possibility to go on excursions, such as skiing or swimming. Special days or evenings for boys are also arranged. These arrangements begin from the individual's life perspective and needs, and are built on the young persons and their subjective orientations, values and skills. It allows them to take a role as key actors in their own transition and integration. In staffs notes in the diaries one can see that staffs value these pedagogical arrangements. It is good that those groups for boys \& girls have started (Viola).

When boys do creative activities, youth leaders often make notes and it is not unusual that they give them praise. The boys have been good they have made Christmas cards, Santa Claus and snowmen (Orchid). If an activity has been attractive to both boys and girls it seems to be important to make a note about it. The Gingerbread house seems to interest both boys and girls (Bluebell).

At the youth club or meeting place boys often play billiards or table tennis in controlled forms, most often with other boys. It is not unusual that this is the only activity they participate in during their visits. Staff has noted that some of them visit just because of the possibility to play billiards. It is a controlled activity and it is regulated. In this research nearly every meeting place and youth club has chosen to have billiards and table tennis. In the 
diaries from the meeting place and youth clubs are several or almost daily notes about playing billiards. Notes like the following are often seen; there has been a lot of billiard playing (Marguerite). This research does not provide any answer regarding why billiards is so important for the fulfillment of young visitors needs.

In this research there seems to be a notion that visitors also prefer manual activities such as painting, drawing, cutting and pasting. These free creative activities are mostly done by girls. A nice evening! I took with me some oil pastel drawing chalk and painted a little and some females joined in (Bluebell). From the diaries one can notice that it is not unusual that the theme for the evenings when girls visit more frequently is that of creative activities or baking. $N N$ (female) and $N N$ (female) did a pie with ice cream, and invited us, Mums!! (Viola).

The embodied use of space by boys seems to be more controlled than the embodiment and use by space of girls. There is an ambition in all youth clubs to have equipment that can attract and fulfill visitor's needs. The staffs are often both male and female. The type of equipment often seen is that of TV games, computer games, music room, TV sets, smaller cinema, parlor games, cards and material for creative activities like graffiti and painting. Although the broad ambition is to have facilities that attract both female and male visitors, nevertheless most of them are males.

\subsection{Influence and Participation}

An example of youth influence and participation is that one can notice that at all youth clubs in this study visitor have been involved in the decoration and design of the facilities. It is very common that visitors have decorated the walls with graffiti and walls are often decorated with pictures and paintings. Visitors have also been able to choose the color of carpets, curtains and other details for design. They can come with suggestions to staff of movies to hire, computer games to buy or excursions. Several have pointed out the horrible color in the ping pong room and the 'painting room' and they absolutely want to help when the time comes for repainting (Bluebell).

Other examples of influence and participation are the youth assembly seen at some of the youth clubs. The youth assembly was here and we set down and talked for a long while. Very funny (Bluebell). The youth club also cooperates with the parents, an association which this quotation reveals; $N N$ and $N N$ came by with the Parents Association, which was nice and it was fun to see the youth club for them (Bluebell).

To stay overnight at the youth clubs seems to be of interest for the visitors. A very nice evening, there were 17 young people who stayed overnight (Marguerite and Orchid). From the notes one can read that it was two girls who had arranged it all. The staff has written in the diaries that it was very well done. Similar notes are made from another youth clubs. Some girls started to plan staying overnight and $N N$ (female, $N N$ (female), NN (female) and $N N$ (female) arranged the overnight theme (Petunia).

This case study show that visitors are invited to participate but it is not interesting for all of them to be active and participate, some visit these places just to "hang around" or talk to other visitors or/and staffers. No one wanted to join the torchlight procession; we think that is unfortunate ... / (Marguerite) and we put forward things to make Eastern pottery with but there was a very little interest for it (Marguerite).

From the diaries one can find that staff try to engage the visitors all the time, we have had a brainstorm (Marguerite). Another way to get young visitors engaged was an initiative from staff to make of 'map of ideas' were the youths could write down their ideas. Used the last hour to really try to have ideas and suggestions from the visitors (Buttercup). This is also seen from another youth clubs. Have made a 'youth binder' were groups who are planning activities can have their notes (Bluebell).

When young visitors come with suggestions the staffs appreciate that. But from the staffers there are no demands regarding doing things, young visitors come of their own will and they do not have to 'do things' if they are not interested.

\subsection{Safety and Sustainability}

From the notes one can say that most of the days are 'calm/quite', but occasionally things happen. One night in January the staff had noted that they had to confiscate an air gun that a boy had brought with him. Both the pistol and the guy had to leave the youth club for the evening (Viola).To work as a youth leader can be very challenging and complicated, which several of the dairy notes bear witness to. An unpleasant thing has happened at the club. I gave a slap to one of the visitors NN. The youths saw it. It feels embarrassing and I have crossed the border. My fault (Buttercup). 
The quotation shows the demands made on the youth leaders' professionalism, competence and self control when handling such a situation. However moments when youth leaders feel very comfortable with the situation are also evident in the diaries. I and NN ascertain that we have started to have good relations with the youths (Bluebell).

To work as a youth leader means that you sometimes need to have deep and difficult conversations about the most intimate issues. Today I had a conversation about sorrow with $N N$ and some other visitors. A friend of them in the same age had committed suicide (Marguerite).

In the notes one can read that youth leaders sometimes complain to the next working youth leaders and can claim if they fight, stand up for your values and if this does no work throw them out (Marguerite), expel them if they misbehave (Marguerite).

The diaries bear witness about how staffs sometimes have to call the police. A visitor had kicked in a door and one of the youth leaders wrote in the diaries. I felt that this was too much. I called the police. When the police came the boys ran away (Buttercup). Many of the notes show that the staffs take a major responsibility for the youths in other scenarios other than when they visit the club. Party again. We have to contact the parents in some way about young people's alcoholic habits (Orchid).

The extent or the rumours about the occurrence of drugs in the neighbourhood often involves the youth leaders at the youth clubs. Had a phone call from a concerned \& anonymous parent about drugs among youths who smoke (Petunia). Sometimes parents that are worried about their children visit the youth clubs to get information about their sons or daughters. Anxious dad came in and looked for his son, $N N$ who had been missing almost a week ... $/$ (Petunia). However parents do not just come to search for their sons and daughters, it seems as though parents also drop in just to say hallo which staff appreciate. Nice when parents visit (Orchid).

However, now and then the police visit the youth clubs without there excising a special situation. The police stopped by (Orchid). This is appreciated both from the youth and the youth leaders. Police $N N$ (female) and Police $N N$ (female) passed by during the evening. Guys love each \& got to play with handcuffs $\odot$ (Viola).

At the youth clubs and similar meeting places youths are not allowed to smoke. There are rules for this and almost all visitors accept these rules but sometimes there are discussions about rules both among staff and visitors. Remember that youth can also say to you that staff NN let me smoke although it is not true. But of course all should have the same rules and I believe that all youth leaders have that (Petunia).

Sometimes more unusual things happen such as staff becoming trapped or that someone has used stink bombs at the youth club. At 22.20 we noticed that some have been shovelling snow into both doors so no one could go out ... NN (female youth leader) jumped out of one of the windows \& shovelled away the snow in front of the personal entrance (Viola).

The following quotation show how an evening started quietly but ended with someone or using stink bombs at the youth club. Started as a quiet evening, but one or a few ruined it all by placing a stink bomb at the youth club (Viola). Order rules recur constantly in the diary entries and it is almost exclusively a record of acting out boys. Loud as usual, $N N$ (male), $N N$ (male) and $N N$ (male) NEVER listen to what you say. Maybe we should become harder and throw them out and show them that we are serious? Otherwise a nice evening $-($ (Viola).

Nevertheless in the diaries there are many happy incidents recorded and one can imagine that the youth leaders are very fond of the youths. It also seems that staffs have been successful at meeting the visitor's needs and expectations. Nice boys here tonight! When they can do things they are interested in they get calm (Viola).

In the local councils the priority is that open leisure activities shall contribute to all young people participating in and influencing those questions which are of concern to them. The target group for open leisure activities in the local council is youth from the age of 13 years and upwards. From the diaries one can notice that the youth club often became the visitors' 'home 'or 'their' club. Among the visitors groups and subgroups are often formed. These groups are closed in nature and may be exclusionary to other groups. There was a group of students here who played table tennis so the youths did not want to be here, they went to the sports hall (Petunia).

To summarize, authorities believe that open leisure activities should be attractive and developed in such manner that visitors influence, develop, and realize ideas. Research has shown that the local council has invested in relatively many meeting places for youth compared to its number of citizens. Most of them are more or less accessible for all people interested in visiting them as they are geographically located in different parts of the local council's geographical area. 


\section{Discussion and Conclusions}

The social construction of space and place by youth is complex and multi-layered. The possibilities or inability to develop young peoples' citizenship differs according to the public space, in this case the youth club or the meeting place. Life experience of public spaces involves testing social dependence and independence, agency and control.

This research can give us some clues about which of these meeting places attract and the activities which young people choose to participate in during their leisure time, in other words their lifestyle choices. It can also give an understanding of the possibilities these meeting places provide for the development of young people's citizenship.

This study indicates that youth clubs and similar meeting places can be important places for a transition to citizenship and integration. However many of the quotations show it is a challenge to develop them as such. Although staff try to stretch the boundaries between the visitors most often stereotypical behaviours is still dominant. I will argue that to some degree available space for activities and association often seems to be used in ways that segregate space and activities for boys and space and activities for girls.

I further argue that youth clubs and similar meeting places for youth are more attractive to boys than to girls. Boys find the environment, facilities and equipment more interesting than girls do. Activities are often traditional female or male activities, boys visiting these meeting places often play billiards or table tennis. As mentioned they come to these places together with other boys and most of the time they participate with boys. Girls use space in different ways; girls are often involved in creative activities such as drawing and painting, baking, watching movies or playing TV games such as 'sing stars'. Most often they carry out these activities together with other girls at the meeting place. It is not unusual that they come to these places together with another girl or a few other girls and stay with them the whole time.

Visitors are often regular visitors and unlike school they come there of their own free will and there is no demand to participate in activities. Visitors have often an expressive life style and it is not unusual that they mistrust the school system. Youth clubs and similar meeting places fit their lifestyle and seem to almost be the only place that can meet their needs and expectations.

My interpretation of the diaries and the notions of the youth leaders is that visitors at these meeting places can talk to staff and other visitors in a safe environment. At these places there are rules for the visitors to follow such as being a drug free place. From the notes in the diaries several examples are given of the youth club as a free zone. From staff notes and their conception of the reality it seems to be important for them to have a professional relationship with authorizes such as the police or with parents. It has also to be taken in account that the diaries are written to be read of colleagues, managers and in some cases researchers. In this research all the notes were kept before the staff known that they were going to be a part of a research study which can strengthen its validity and reliability.

The staff is both male and female and they are of different ages. Visitors are often regular visitors, in this local council about $5-10 \%$ of the potential visitors come to these places established by and of the local council.

From the quotations it is seen that staff sometimes challenge the visitors and vice versa as visitors have to follow the rules. The staffs have to balance between being close to the visitors and at the same time having some distance. Otherwise they might take the risk that the visitors might not come back.This can be interpreted as an example of how young citizens can develop their citizenship and an example of what Yuval-Davis (2002) talk about as the theatre of citizenship taking place on a daily basis. Young people negotiate their citizenship on a daily basis. It is possible to recognize citizenship as a process that is produced sometimes reproduced and articulated. It is also possible to argue that the written texts in the diaries can be a part of a variety of power related functions such as between staffs and staffs and visitors. Youth leaders can express them self in different ways about the core values of citizenship and the ways in which gender differences shapes their representations of the citizen. Arnot (2009) state the task now for educationalists is to use the 'gender global gaze' to uncover the inequalities of gender within contemporary civil society.

To be critical some questions must be raised about the fact that these youth clubs and similar meeting places mostly carter for boys needs. Firstly, approximately $6-10 \%$ of the young citizens, mostly boys, between the ages 13-25 years old visit the clubs, that mean that $90 \%$ of the possible young people's have chosen not to visit the youth clubs and similar meeting places. Secondly, should society be satisfied with having established space for young people such as youth clubs and similar meetings places where mostly boys stay or "hang around", play ping pong and billiards when this study clearly indicates that youth clubs and similar meeting places can be 
important places for a transition to citizenship. I will suggest that these possibilities must be taken seriously by those who the question concerns, in this case the politicians.

\section{References}

Ahmad, I. (2006). Teaching Government in Social Studies: Political Scientists Contributions to Citizenship Education. The Social Studies, 1997-1998.

Alvesson, M., \& Sköldberg, K. (1994). Tolkning och reflektion. Vetenskapsfilosofi och kvalitativ metod. [Interpretation and reflection. Philosophy of science and qualitative method]. Lund: Studentlitteratur.

Arnot, M., \& Dillabough, J-A. (2000). Challenging Democracy. International perspectives on gender, Education and Citizenship. London and New York: Routledge

Arnot, M. (1997). 'Gendered Citizenary' New feminist perspectives on Education and Citizenship. British Educational research Journal, 23(3), 275-295.

Arnot, M. (2006). Gender equality, pedagogy and citizenship: Affirmative and transformative approaches in the UK. Theory and Research in Education, 4, 131. http://dx.doi.org/10.1177/1477878506064539

Arnot, M. (2009). A global conscience collective?: Incorporating gender injustices info global citizenship education. Education, Citizenship and Social Justice, 4, 117. http://dx.doi.org/10.1177/1746197909103932

Banks, J., A. (2008). Diversity, Group Identity, and Citizenship Education in a Global Age. Educational Researcher, 37(3), 129-139. http://dx.doi.org/10.3102/0013189X08317501

Block, J. H. (1983). Differential premises arising from differential socialization of the sexes: Some conjectures. Child Development, 54, 1335-1354. http://dx.doi.org/10.2307/1129799

Börjesson, M., \& Palmblad, E. (red.) (2007). Diskursanalys i praktiken. [Discource analysis in practice]. Helsingborg: Liber.

Bruhn, Jensen, K. (1989). Discourses of Interviewing: Validating Qualitative Research Findings Through Textual Analysis. In Kvale, S. (1989). (Eds). Issues of Validity in Qualitative research. Lund: Studentlitteratur.

Connell, R., W. (1987). Gender \& Power. Society, the Person and Sexual Politics. Cambridge: Polity Press.

Deutch, F., M. (2007). Undoing gender. Gender \& Society, 21, 106. http://dx.doi.org/10.1177/0891243206293577

Eaton, W. O., \& Enns, L., R. (1986). Sex differences in human motor activity level. Psychological Bulletin, 100, 19-28. http://dx.doi.org/10.1037/0033-2909.100.1.19

Eckert, P., \& McConnell-Ginet S. (1995). Constructing meaning, constructing selves: Snapshots of language, gender and class from Belten High, In Hall, K \& Bucholtz, M (Ed). Gender Articulated Language and the Socially Constructed Self. New York: Routledge.

Faulks, K. (2006). Rethinking citizenship education in England: Some lessons from contemporary social and political theory. Education, Citizenship and Social Justice. (2006:1:123). (Online, 2008-05-21). Retrieved from http://www.sagepublications.com

Gordon, T., Holland, J., \& Lahelma, E. (2000). Making spaces: Citizenship and difference in schools. Basingstoke: Palgrave Macmillan. http://dx.doi.org/10.1057/9780230287976

Gordon, T. (2006). Girls in education: Citizenship, agency and emotions. Gender and Education, 18(1), 1-15. http://dx.doi.org/10.1080/09540250500194880

Helve, H. (2001). Reflexivity and Changes in Attitudes and Value Structures. In Helve, H \& Wallace, C. (2001). Youth, citizenship and Empowerment. (ed). Burlington: Ashgate Publishing Company.

Kohlbacher, F. (2006). The use of Qualitative Content Analysis in Case Study Research. Qualitative Social Resarch, 7(1), 21.

Kovacheva, S., \& Pohl, A. (2007). Disadvantage in youth transitions: constellations and policy dilemmas. In Colley, H., Boetzelen, P., Hoskins, B \& Parveva, T. (2007). (Eds). Social inclusion and young people: braking down the barriers. Council of Europe Publishing. F-67075 Strasbourg Cedex. Retrieved Nov. 8. 2010, from http://book.coe.int 
Lindström, L. (2009). Leisure activities and youth citizenship: what local councils tell about youths' leisure from the perspective of citizenship on their homepages. Luleå: Luleå tekniska universitet, 2009. (Doctoral thesis / Luleå University of Technology).

Lister, R. (1997). Citizenship: Towards a Feminist Synthesis. Feminist Review, 57, 28-48. http://dx.doi.org/10.1080/014177897339641

Lockyer, A. (2003). The Political Status of Children and Young people. In Lockeyr, Crick and Annette, (eds). (2003). Education for Democratic Citizenship. Issues of Theory and Practice. Gateshead: Tyne \& Wear.

Marshall, T., H., \& Bottomore. (1996). Citizenship and Social Class. Illinois: Pluto Classic.

Mc Knee, A. (2003). Textual Analysis: A Beginner London, GBR: Sage Publication.

McDonagh, E. (2002). Political Citizenship and democratization: The Gender paradox. The American Science review, 96(3), 535-552.

Meer, S., \& Sever, C. (2004). Gender and Citizenship. Overview report. Institute of Development Studies January 2004. Retrieved August 18, 2010, from http://www.ids.ac.uk/bridge

Mouffe, C. (1992). 'Feminism, Citizenship and Radical Democratic Politics 'In J. Butler and J.W Scott (eds). Feminists Theories the Political. London and New York: Routledge.

O'Connor, J. (1993). Gender, Class and Citizenship in the Comparative Analysis of Welfare State regimes: Theoretical and Methodological Issues. The British Journal of Sociology, 44(3), 501-518. http://dx.doi.org/10.2307/591814

Parkin, W. (2000). Protesting like a girl: embodiment, dissent and feminist agency. Feminist Theory, 1(1), 59-78. http://dx.doi.org/10.1177/14647000022229065

Pellegrini, A., D., \& Perlmutter, J., C. (1989). Classroom contextual effects on children's play. Development Psychology, 25, 289-296. http://dx.doi.org/10.1037/0012-1649.25.2.289

Philips, L., \& Jörgensen W., M. (2002). Discourse Analysis as Theory and Method. London: Sage Publications.

Pomerleau, A., Bolduc, D., Malcuit, G., \& Cossette, L. (1990). Pink or Blue: Environmental Gender Stereotypes in the First Two years of Life. Sex Roles, 22(5/6), 1990.

Schild, H, Pererva, Y., \& N, Stockwell. (2009). Preface: European citizenship and young people in Europe. In Dolejsiová, D., \& López, M., A., G. (2009). (eds). European citizenship - in the process of construction .... Challenges for citizenship, citizenship education and democratic practice in Europe. Council of Europe Publishing. F-67075 Strasbourg Cedex. Retrieved Nov. 15, 2010, from http://book.coe.int

Shaw, S., M. (1994). Gender, Leisure, and Constraint; Towards a Framework for the Analysis of Women's leisure. Journal of Leisure research, 26(1), 8-22.

Torres, C., A. (1998). Democracy, Education, and Multiculturalism: Dilemmas of Citizenship in a Global World. Comparative Education Review, 42(4), 421-447. http://dx.doi.org/10.1086/447522

Turner. B., S. (1993). Citizenship and Social Theory. London. SAGE Publications.

Werbner, P., \& Yuval-Davis, N. (1999). Women and the new Discourse of Citizenship. London: Zed Books.

West, C., \& Zimmerman, D., H. (1987). Doing gender. Gender and Society, 1(2), 125-151. http://dx.doi.org/10.1177/0891243287001002002

World Economic Forum. (2008). The Global gender Gap Report. Switzerland: Geneva. 8 Online, 2011-03-18.

Yin, R. K. (1994). Case study research: design and Methods. (2. ed.) Thousand Oaks, CA: Sage.

Yuval-Davis, N. (1997). Gender \& Nation. London: Sage Publications Ltd.

Yuval-Davis, N. (2002). Citizenship, territoriality and the gendered construction of difference. In Isin, F, I. (2000). (Ed.) Democracy, citizenship and the global city. London and New York: Routledge, Taylor \& Francis Group.

\section{Author}

Lisbeth Lindström works as a lecturer in social sciences at the University of Technology in Luleå, Sweden. The focus of her research concerns youth and citizenship. Her interest is to study young people's experience of influence and participation as visitors at different meeting places such as youth clubs and similar environment available for them during their leisure time. A main question in her research is what kind of citizenship these environment support. 